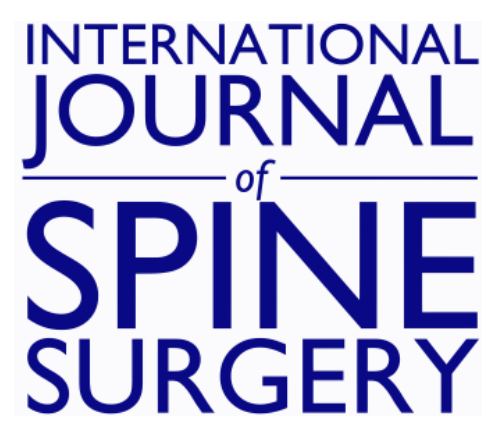

\title{
Enchondroma Protuberans of the Transverse Process of D8 Vertebra Extending to the 7th and 8th Ribs: A Rare Case Report
}

\author{
MURAHARI PENKULINTI, HARSHAVARDHAN RAORANE, VINAYAK SANTOSH \\ KALAKATA, SATISH KUMAR VEMURI, RAJKIRAN REDDY BANALA and SUBBAIAH \\ GPV
}

Int J Spine Surg 2018, 12 (1) 43-48

doi: https://doi.org/10.14444/5008

http://ijssurgery.com/content/12/1/43

This information is current as of April 26, 2023.

Email Alerts Receive free email-alerts when new articles cite this article. Sign up at: http://ijssurgery.com/alerts 


\title{
Enchondroma Protuberans of the Transverse Process of D8 Vertebra Extending to the 7th and 8th Ribs: A Rare Case Report
}

\author{
MURAHARI PENKULINTI, ${ }^{1,2}$ HARSHAVARDHAN RAORANE, ${ }^{2}$ VINAYAK SANTOSH KALAKATA, ${ }^{1}$ \\ SATISH KUMAR VEMURI, ${ }^{2}$ RAJKIRAN REDDY BANALA, ${ }^{2}$ SUBBAIAH GPV ${ }^{1,2}$ \\ ${ }^{I}$ Spine Department, Star Hospitals, Road No. 10, Banjara Hills, Hyderabad, Telangana, India, ${ }^{2}$ SMART, Sunshine Hospitals PR Road, Secunderabad, \\ Telangana, India.
}

\begin{abstract}
Background: Enchondroma protuberans (EP) is rare, benign cartilaginous bone tumor arising from the intramedullary cavity of long bones and usually protrudes beyond the cortex with an exophytic growth pattern resembling osteochondroma. This study reports on a rare case of EP arising from the transverse process of the D8 vertebra and extending to the adjacent 7 th and 8 th ribs and the paraspinal tissues.

Methods: A 45-year-old female patient came in with complaints of upper back pain radiating up to the left costal margin for the past 6 months. There were no parasthesias, and there was no history of any sensory or motor symptoms. On physical examination there was midline and left paraspinal tenderness over the D6 to D8 region. Anteroposterior and lateral X-ray images revealed a well-defined oval ossific mass lesion over the lateral aspect of the D8 vertebra, extending to the 7th and 8th ribs on the left side, and multiple bridging osteophytes were noted. Computed tomography scan showed an ossific mass lesion arising from the D8 transverse process with extension to the adjacent 7th and 8th ribs; its margins were well defined, with no periosteal reaction. Magnetic resonance imaging showed a welldefined expansile mass lesion arising from the transverse process of the D8 vertebra matrix; it was was isointense with adjacent marrow and had no evidence of calcifications or vascular flow voids and no encroachment into the spinal canal.

Results: Complete resection of the mass lesion with the adjacent part of the 7th and 8 th ribs and with intramedullary curettage was performed and sent for histopathologic examination. Histopathology showed bony trabeculae with normal mucosal elements, and a mild hypercellularity with binucleation. Chondrocytes in the myxoid matrix located in round lacunae were compatible with enchondroma, with no evidence of atypia. The postoperative period was uneventful, and after 12 months there were no signs of recurrence noted in computed tomography scan.

Conclusions: EP is a rare presentation in the dorsal spine; it should be considered in the differential diagnosis of osteochondroma, enchondroma, chondrosarcoma, and periosteal chondroid tumors.
\end{abstract}

Lumbar Spine

Keywords: enchondroma protuberans, magnetic resonance imaging (MRI), osteochondroma, enchondroma, chondrosarcoma, periosteal chondroid tumors

\section{INTRODUCTION}

Enchondroma protuberans (EP) is a rare, benign cartilaginous bone tumor that arises from the intramedullary cavity of long bones and that usually protrudes beyond the cortex, with an exophytic growth pattern resembling osteochondroma. Only a few cases of EP have been reported in phalanges and metacarpals. To the best of our knowledge no case of spinal EP originating from the transverse process and extending to the ribs has been reported thus far. We give here a case report of a 45-year-old female patient with EP originating from the transverse process of the D8 vertebra and extending to the corresponding 8th and 7th ribs and paraspinal tissue.

\section{CASE REPORT}

A 45-year-old female patient came in with complaints of upper back pain radiating up to left costal margin that had lasted 6 months; there was no paresthesia and there was no history of any sensory or motor symptoms. No associated constitutional symptoms like fever, loss of weight, or appetite. On physical examination there was midline 


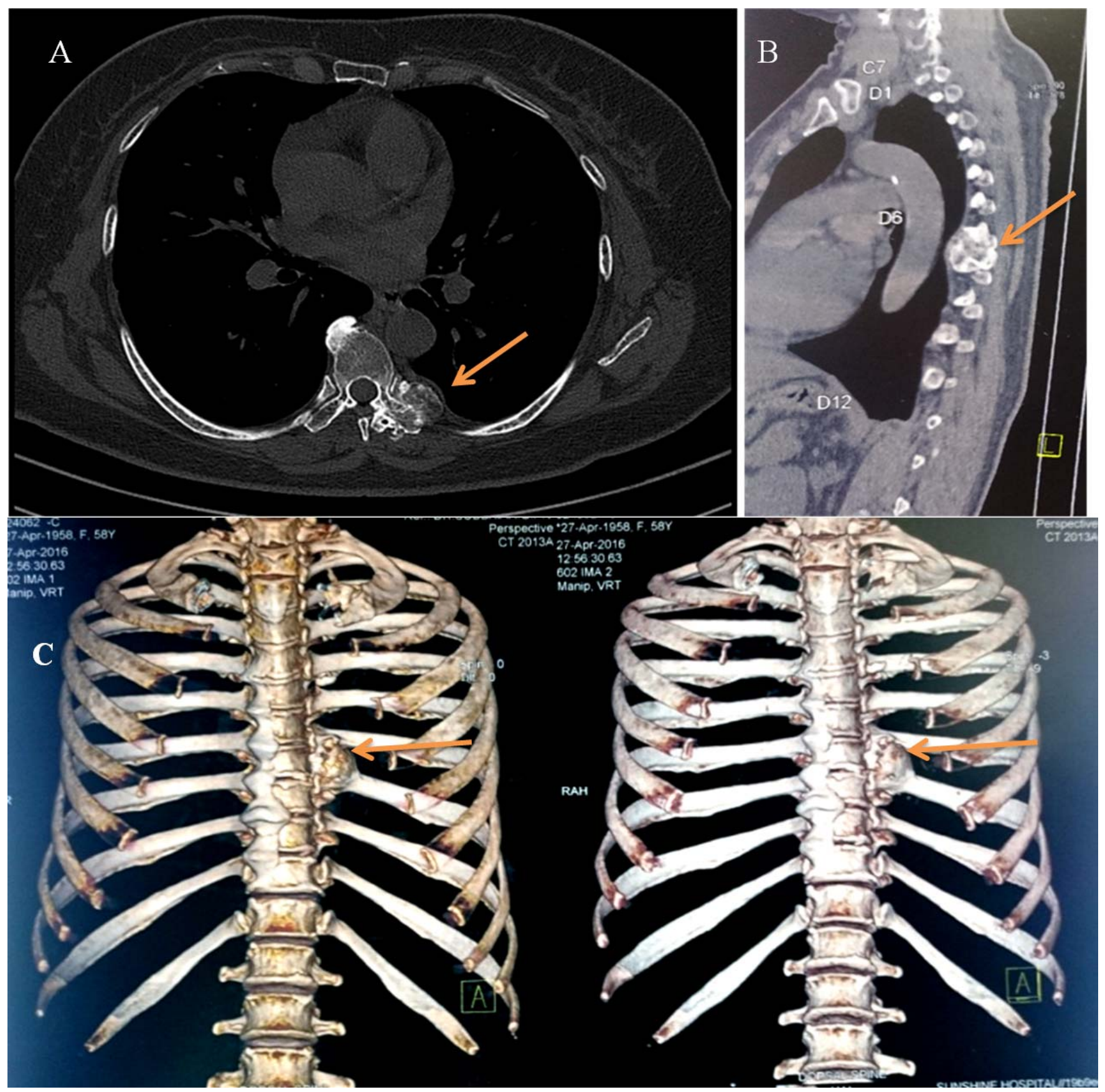

Figure 1. (A and B) Computed tomography (CT) scan image of axial and sagittal section showing ossific process extending to the 7th and 8th ribs left side, indicated by bold orange arrow. (C) Three-dimensional reconstruction CT scan mass arising from the D8 transverse process and extending to adjacent ribs.

and left paraspinal tenderness over the D6 to D8 region, there was no regional deformity, overlying skin was normal, and neurologic examination was normal.

Anteroposterior and lateral X-ray images revealed a well-defined oval ossific mass lesion over the lateral aspect of the D8 vertebra that extended to the 7 th and 8th ribs on the left side, with multiple bridging osteophytes noted. Paraspinal shadow was normal
Computed tomography (CT) scan showed an ossific mass lesion arising from the D8 transverse process with extension to the adjacent 7 th and 8 th ribs, well-defined margins, and no periosteal reaction; vertebral bodies and posterior elements were normal (Figure 1A and B).

Magnetic resonance imaging (MRI) showed a well-defined expansile mass lesion arising from the transverse process of the D8 vertebra matrix that 


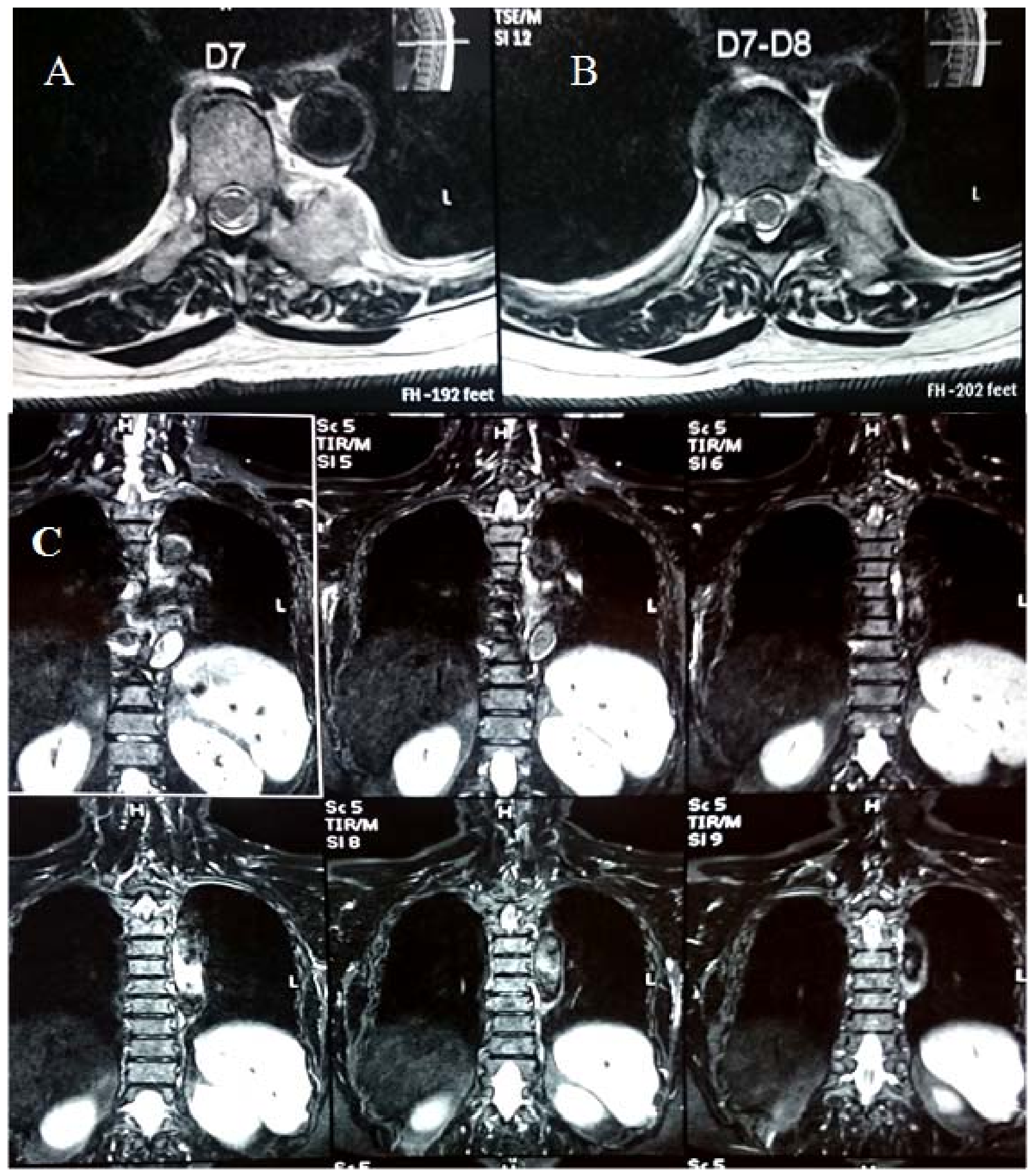

Figure 2. ( $A$ and B) T2-weighted images well defined expansile mass lesion arising from transverse process of $D_{8}$ vertebra with matrix isointense to adjacent marrow. (C) Short TI inversion recovery image showing well defined expansile mass heterogenous in signal intensity arising from transverse process of $D_{8}$ vertebra.

was isointense with adjacent marrow and that had no evidence of calcifications or vascular flow voids, and no encroachment into the spinal canal (Figure 2).
Complete resection of mass lesion with the adjacent parts of the 7 th and 8th ribs with intramedullary curettage was performed and sent for histopathologic examination. Histopathology 


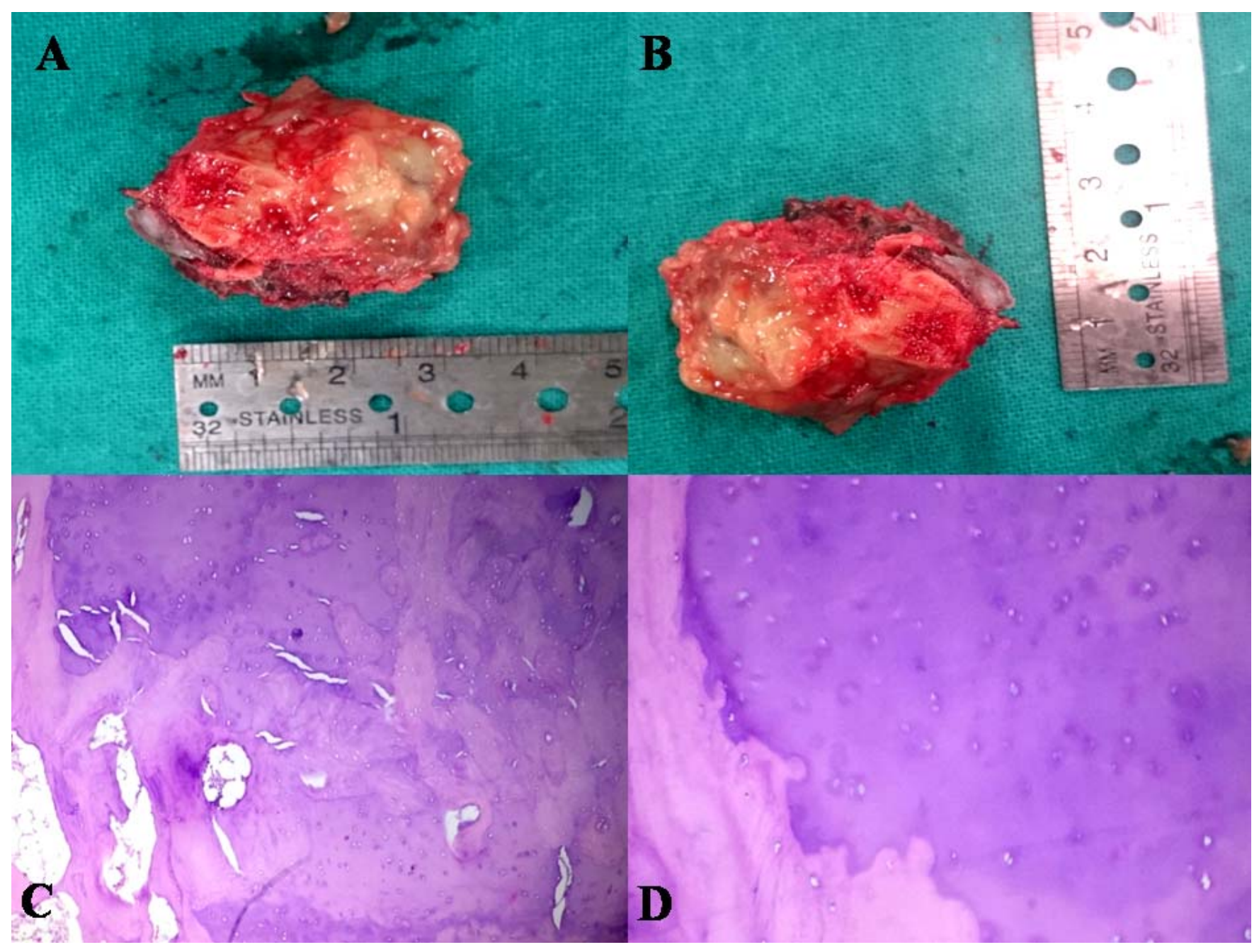

Figure 3. (A and B) Gross specimen of mass of enchondroma with part of 7th and 8th rib. (C and D) Histopathology showing chondroid lesion peripherally rimmed by osteoid, chondrocytes in myxoid matrix located in round lacunae, compatible with enchondroma.

showed bony trabeculae with normal mucosal elements, and a mild hypercellularity with binucleation. Chondrocytes in myxoid matrix located in round lacunae were compatible with enchondroma, with no evidence of atypia (Figure 3).

The postoperative period was uneventful, and after 12 months there were no signs of recurrence noted in CT scan (Figure 4).

\section{DISCUSSION}

EP is rare, benign cartilaginous tumor of the long bones that arises from the intramedullary cavity and that usually protrudes beyond the cortex. Chondromas in the spine are a rare pathologic entity, accounting for approximately $3 \%$ of all chondromas. ${ }^{8}$

There have been only a few reported cases of EP, and all were located in the hands, ribs, and humerus regions.
Chondroma of the spine may be derived from a hyperplasia of immature spinal cartilage with migration outside the vertebral axis or from metaplasia of the connective tissue in contact with the vertebra or the annulus fibrosus. ${ }^{6}$

Enchondroma almost always appears as a welldefined osteolytic lesion that is usually located within the metadiaphysis of long bone. Because of bone expansion the cortex may appear thin but usually remains intact. Expansion of enchondroma through the cortex is rare, and if accompanied by a cortical defect, will result in EP.

Radiologically, EP is presented as a well-defined intramedullary osteolytic lesion and may be accompanied by fine matrix calcification, cortical expansion and cortical defect, and round, well-defined soft tissue expansion. ${ }^{5}$ 


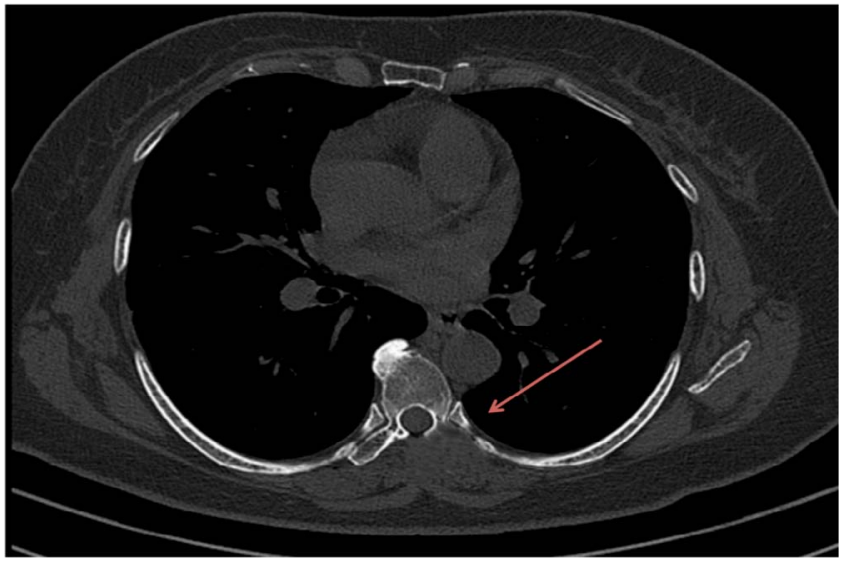

Figure 4. Axial computed tomography scan image of $D_{8}$ vertebra with adjacent ribs showing no growth post one year after surgery, indicated by bold red arrow.

Radiologically, EP resembles osteochondroma; however, osteochondroma can be excluded on the basis of the presence of cartilage cap with underlying trabecular bone. EP also has geographic intramedullary osteolytic lesion. ${ }^{9}$ It is important to distinguish EP and osteochondroma when planning surgical treatment to prevent potential chondrosarcomatous transformation. In the case of osteochondromas, the regions containing cartilage are generally confined to the cap; therefore, excision of the cap is sufficient. ${ }^{7}$ In the case of EP, however, deposits of cartilage are found not only in the protruded tumor but also within the adjacent underlying medulla of the host bone. Thus, EP should be treated with the combination of resection of cartilage containing protuberance and intermedullary curettage. ${ }^{9}$

The typical presentation of EP in magnetic resonance (MR) images is as a well-defined intramedullary lesion with low signal intensity in T1weighted image and high signal intensity in $\mathrm{T} 2$ weighted and short tau inversion recovery sequences accompanied by cortical expansion and cortical defect.

Although this benign tumor is usually diagnosed by conventional radiography (X-ray), ${ }^{2,3}$ sometimes conventional X-ray alone is not sufficient for diagnosis. $^{2}$ Conventional radiographs may not detect protruding mass or cortical expansions. MR images can reveal the connection between the intramedullary portion and the exophytic protrusion better than conventional radiography can. Also, MR images can clearly delineate the cortical defect, which is essential in the diagnosis of EP. ${ }^{1,4}$
MR imaging studies of our case report were similar to previously reported cases of EP.

It is essential to consider EP in the differential diagnosis of osteochondroma, enchondroma, periosteal chondroid tumors, and chondrosarcoma. Osteochondroma is continuous with the bone, originating in the bone and consisting of a dense osteoid formation in the cortex and medulla. Periosteal chondroma is a benign cartilaginous tumor of periosteal origin that occurs in young adults.

Malignant transformations of benign enchondroma to chondrosarcomas have been reported, but thus far no malignant transformations for EP have been reported. ${ }^{10}$

\section{CONCLUSION}

$\mathrm{EP}$ is a rare presentation in the dorsal spine; it should be considered in the differential diagnosis of osteochondroma, enchondroma, chondrosarcoma, and periosteal chondroid tumors.

\section{REFERENCES}

1. Beytemur O, Adanir O, Oncu M, Tetikkurt US. A rare cartilaginous tumor in the phalangeal bone: enchondroma protuberans. Acta Orthop Traumatol Turc. 2014;48(3):379-381.

2. Dagum AB, Sampson SP. Enchondroma protuberans: a case report. J Hand Surg. 1998;23(2):338-341.

3. Caballes RL. Enchondroma protuberans masquerading as osteochondroma. Hum Pathol. 1982;13(8):734-739.

4. An YY, Kim JY, Ahn MI. Enchondroma protuberans of the hand. AJR Am J Roentgenol. 2008;190(1):40-44.

5. Ceulemans LJ, Verheyen L, Vanhoenacker FM. Enchondroma protuberans of the rib. JBR-BTR. 2011;94(6):354.

6. Lozes G, Fawaz A, Perper H. Chondroma of the cervical spine: case report. J Neurosurg. 1987;66(1):128-130.

7. Slesarenko YA, Sampson SP, Gould ES. Recurrent enchondroma protuberans: a case report. J Hand Surg. 2005;30(6):1318-1321.

8. Erten SF, Kocak A, Mizrak B. An end-plate chondroma mimicking calcified lumbar disc herniation: a case report and review of the literature. Neurosurg Rev. 1999;22(2-3):145-148.

9. Crim JR, Mirra JM. Enchondroma protuberans: report of a case and its distinction from chondrosarcoma and osteochondroma adjacent to an enchondroma. Skeletal Radiol. 1990;19(6):431-434.

10. Müller PE, Dürr HR, Nerlich A. Malignant transformation of a benign enchondroma of the hand to secondary chondrosarcoma with isolated pulmonary metastasis. Acta Chir Belg. 2004;104(3):341-344.

Disclosures and COI: No authors have conflicts of interest associated with this study. 
Corresponding Author: GPV Subbaiah, Spine Department, Road No. 10, Banjara Hills, Hyderabad 500032, India. Email: drgpvsubbaiahgoli@ gmail.com

Published 30 March 2018
This manuscript is generously published free of charge by ISASS, the International Society for the Advancement of Spine Surgery. Copyright $\subset 2018$ ISASS. To see more or order reprints or permissions, see http://ijssurgery.com. 